\title{
CD14 Gene Variants and Their Importance for Childhood Croup, Atopy, and Asthma
}

\author{
Donna C. Rennie, ${ }^{1,2}$ Chandima P. Karunanayake, ${ }^{1}$ Yue Chen, ${ }^{3}$ Kazuko Nakagawa, ${ }^{4}$ Punam \\ Pahwa, ${ }^{1}$ Ambikaipakan Senthilselvan, ${ }^{5}$ and James A. Dosman ${ }^{1}$ \\ ${ }^{1}$ Canadian Centre for Health and Safety in Agriculture, University of Saskatchewan, P.O. BOX 23, 104 Clinic Place, \\ Saskatoon, SK, Canada S7N 5E5 \\ ${ }^{2}$ College of Nursing, University of Saskatchewan, University of Saskatchewan, 104 Clinic Place, Saskatoon, SK, Canada S7N 5E5 \\ ${ }^{3}$ Epidemiology \& Community Medicine, University of Ottawa, 451 Smyth Road, Ottawa, ON, Canada K1H 8 M5 \\ ${ }^{4}$ Kumamoto University, 2-40-1 Kurokami Chuo-ku, Kumamoto 860-8555, Japan \\ ${ }^{5}$ School of Public Health, 3-349 Edmonton Clinic Health Academy, 1140587 Avenue, Edmonton, AB, Canada T6G 1C9
}

Correspondence should be addressed to Donna C. Rennie; donna.rennie@usask.ca

Received 28 June 2013; Revised 1 October 2013; Accepted 9 October 2013

Academic Editor: Chih-Hung Ku

Copyright (C) 2013 Donna C. Rennie et al. This is an open access article distributed under the Creative Commons Attribution License, which permits unrestricted use, distribution, and reproduction in any medium, provided the original work is properly cited.

\begin{abstract}
Background. The CD14 gene has an important role in the detection of inflammatory provoking pathogens and in the ensuing signaling of the innate immune response. We assessed the role of CD14 C-159T, G-1359T in the expression of asthma, croup, and allergy in Canadian school children of ages 6 to 14 years. Methods. Children attending schools in a rural community participated in a cross-sectional survey of respiratory health. Following consent, we conducted clinical assessments to collect buccal swabs for genotyping and perform skin prick testing (SPT) to determine atopic status. Genotyping and SPT results were available for 533 and 499 children, respectively. Separate multivariable analyses that included both polymorphisms were conducted for each phenotype. Results. The prevalence of asthma, allergy, and croup was $18.6 \%, 22.4 \%$, and $6.6 \%$, respectively. Children with the T/T variant of CD14 G-1359T were more likely to have physician diagnosed asthma (26.8\%). Children with C/C variant of CD14 C-159T had a significantly lower prevalence of croup (2.6\%). Haplotype analyses of the two CD14 polymorphisms showed that individuals with the T|T haplotype combination were significantly more likely to have asthma $(P=0.014)$. Conclusions. In this study, CD14 variants are important for the expression of croup and asthma but not atopy.
\end{abstract}

\section{Introduction}

Respiratory conditions such as asthma and croup are leading causes of hospitalization and emergency room use by children [1-3]. Asthma and allergy are common childhood conditions, and both genetic and environmental factors influence their expression [1]. The inflammatory airway responses associated with these conditions result from the stimulation by external agents of the TLR4 inflammatory pathway through genes such as CD14 located on the surface of immune response cells in the lungs as well as other organs. Both TLR4 and CD14 genes are codependent with MD2 in their roles as signalers of other mediators in the innate response to pathogens [1]. Unlike TLR4 A896G, a functional polymorphism in the Toll signaling pathway, whose primary response on the cell membrane is to the presence of lipopolysaccharide (LPS) from gram-negative bacteria, the CD14 gene appears to have a broader response to pathogen recognition [4-6]. It has a central role in innate immunity, as it can interact with several ligands, including LPS from gram-negative bacteria, components from grampositive bacteria, fungi, and viruses [5]. CD14 has also been suspected to be a crucial link between innate and adaptive immunity in response to environmental antigens [3].

The associations of a history of croup and a common viral respiratory infection with CD14 have not been studied in young children although the association of croup with asthma is well known $[7,8]$. While recurrent croup has been shown to 
be associated with gastroesophageal reflux and family history of croup $[9,10]$, its association with atopy is mixed [8-10]. Croup occurs in approximately $9 \%$ of children [7] and is more common in boys $[8,11]$. As a recurring condition, it accounts for approximately $15 \%$ of emergency room visits per year by children [12].

The single nucleotide polymorphism (SNP) CD14 C$159 \mathrm{~T}$, located in the promoter region of the CD14 gene on chromosome 5, is the most widely studied of the CD14 polymorphisms. This SNP has been identified as being important in atopic responses that include serum $\operatorname{IgE}$ sensitization $[13,14]$ and positive skin prick testing to allergens [14-17]. It has also been known to be associated with decreased lung function [18] and increased wheeze [17-19]. These associations appear to be modified by age $[17,20]$. However, the findings of the association of CD14 polymorphisms with atopy and serum IgE are still inconclusive with several studies finding no association [19-23]. Furthermore, studies assessing the role of the CD14 gene on asthma have focused primarily with the $-\mathrm{C} 159 \mathrm{~T}$ polymorphism and have found no association $[14,16,18,20-24]$, although one study identified an association with a decreased risk of atopic asthma for children with the T/T genotype of -C159T [25].

While CD14 C-159T has been well recognized as a marker for the true atopic-causing variant [26], it is suggested that haplotype combinations with less recognized SNPs of this gene may capture more variability in the disease trait than any one genotype alone [27]. CD14 G-1359T, in linkage disequilibrium with CD14 C-159T [28], has not been well studied for its importance for atopy and asthma. In one study the G/G genotype of - 1359 was more common in mite sensitive children [23] and less common in European adults whose skin prick test (SPT) was positive [14].

The current investigation assessed the role of CD14, specifically CD14 SNPs C-159T and G-1359T, in the expression of asthma, croup, and atopy in a general rural Canadian population of Caucasian children. We also assessed the haplotype-trait associations for CD14 SNPs with atopy, asthma, and croup.

\section{Methods}

In 2004 we conducted a cross-sectional study of respiratory outcomes and potential risk factors in young Canadian children (6-14 years) living in the primarily Caucasian rural community of Humboldt in Saskatchewan (population 5500). Following approval from local school boards, all children attending any of the three primary schools (grades 1 to 8 ), were approached for the study. The self-administered questionnaire, based on the ATS standardized children's respiratory questionnaire [29] and a questionnaire used in the 1993 Children's Humboldt Study [30], was distributed through the schools to parents of attending students. A separate lifestyle questionnaire assessing smoking history, physical activity, and eating patterns was completed by children 12 years or older at the time of school based clinical assessments.
The questionnaire provided information on sociodemographic factors, household exposures, and family history (parental and siblings) of pulmonary conditions including asthma and croup. Asthma was defined as a positive response to a previous or current history of doctor diagnosed asthma. Croup was identified as a past history of doctor diagnosed croup.

A history of farming exposure was present if the child currently lived on a farm or had participated in any of the following farming activities on a regular basis in the past 12 months: haying, harvesting, playing on hay bales, feeding livestock, cleaning pens or barns or emptying or filling grain bins. A positive history of environmental tobacco smoke exposure (ETS) was identified by a report of any smoking by family members in the home of study participants. For children 12 years and over, the definition of ETS exposure also included a positive report of either the participant smoking at least one cigarette in the past 12 months or being present when peers were smoking.

2.1. Skin Testing for Allergies. Atopy was assessed by a positive skin prick test (SPT) of $\geq 3 \mathrm{~mm}$ compared with a saline control to any of the following allergens: D. pteronyssinus, mixed grasses (Western Allergy, Vancouver, CA) D. farina, Fel d 1, Alternaria, and positive (histamine) and negative (saline) controls (Omega Laboratories and Hollister-Stier, Mississauga, CA) [31].

2.2. DNA Extraction and Genotyping. Buccal smears for DNA assessment following the protocol of Richards et al. [32] were taken from both the right and left buccal cavities of the mouth following a 30-second mouth rinse with clear water. Swabs were air dried and sealed in zip lock pouches for transport to the laboratory. In the laboratory, the buccal smear was immersed in $600 \mu \mathrm{L}$ of $50 \mathrm{nM} \mathrm{NaOH}$ contained in a polypropylene microcentrifuge tube and vortexed. The tube, containing the swab, was heated at $95^{\circ} \mathrm{C}$ for 30 minutes. The swab was carefully removed from the tube, leaving behind any residual liquid in the tube. The DNA solution was then neutralized with $60 \mu \mathrm{L}$ of $1 \mathrm{M}$ Tris, $\mathrm{pH} 8.0$, and vortexed again. The buccal DNA was stored at $4^{\circ} \mathrm{C}$. The polymorphisms were genotyped by polymerase chain reactions (PCR) and restriction enzyme digestion. Reagents for both CD14 C159T and G-1359T PCR were 10x Gen Taq universal buffer, dNTPs $(2,5 \mathrm{mM})$, and Taq polymerase $\% \mathrm{u} / u \mathrm{~L}$. For CD14 C$159 \mathrm{~T}$, the primers used to amplify the promoter regions were $5^{\prime}$-GTG CCA ACA GAT GAG GTT CACC- $3^{\prime}$ and $5^{\prime}-\mathrm{GCC}$ TCT GAC AGT TTA TGT AAT C-3' . For CD14 G-1359T, the primers used were $5^{\prime}$-CTC AGG AAT CTG AGG CAA GA$3^{\prime}$ and $5^{\prime}$-CCC TAG ACC TCT GGG GAA AG-3'. Reagents used for restrictive enzyme digestion were Ava II $(10 \mathrm{u} / \mu \mathrm{L}$ for $(\mathrm{C}-159 \mathrm{~T}))$ and Fok I $(4 \mathrm{u} / \mu \mathrm{L}(\mathrm{G}-1359 \mathrm{~T}))$. Products for all genotyping were then analyzed on a $3.0 \%$ agarose gel, following ethidium bromide staining.

2.3. Statistical Analysis. Hardy-Weinberg tests for homogeneity of polymorphisms were conducted for the 2 selected 
SNPs. Chi-squared tests were used to examine the associations between demographic characteristics and phenotypes (asthma, atopy, and croup). Fisher's exact tests were used to examine the associations between genotypes/haplotypes and asthma, atopy, and croup. Separate logistic regression models for phenotypes were used to examine associations with CD14 (C-159T and G-1359T) polymorphisms and haplotypes after adjusting for age, sex, passive smoking, and history of farm exposure. SNPs were examined jointly in each model by including them as independent variables in the models. SPSS Windows Version 18 (SPSS Inc., IL, USA) and the R statistical software package [33] were used for statistical analyses.

\subsection{Linkage Disequilibrium (LD) and Haplotype-Trait Asso-} ciation for CD14 SNPs. Before performing the haplotypetrait association, assessment of LD between the two SNPs of the CD14 gene was performed using $\mathrm{D}^{\prime}$ statistic [31]. A value of $\mathrm{D}^{\prime}$ closer to one assumed a higher level of $\mathrm{LD}$. The association between haplotypes ( $\mathrm{C} \mid \mathrm{G}$ (referent), $\mathrm{C}|\mathrm{T}, \mathrm{T}| \mathrm{G}$, and $\mathrm{T} \mid \mathrm{T})$ and respiratory phenotypes was performed in the $\mathrm{R}$ package [33] using logistic regression methods for each of the outcomes. The parameters were estimated using an expectation-maximization (EM) algorithm [34].

The study was approved by the Biomedical Research Ethics Board of the University of Saskatchewan. Parental and child informed consents/assents for all testing were obtained. Children could refuse participation any time during the study.

\section{Results}

The response rate to the survey was $90.6 \%$ with 566 children returning questionnaires. Very few parents did not consent to genetic testing of their children $(n=28,4.9 \%)$. Genotyping was unsuccessful for 2 children, and results for 3 children reported as non-Caucasian were excluded from the analysis. There were 533 children with results for all SNPs under study. The mean age of children was 9.9 years (standard deviation \pm 2.32 years). SPT results were available for 499 children. The prevalence of asthma and croup was $18.6 \%$ and $6.6 \%$, respectively. The prevalence of atopy was $22.4 \%$.

Table 1 provides the distributions within the study population of personal characteristics and exposures of interest for each of the outcomes of asthma, any atopy, and croup. More boys than girls were sensitized to at least one allergen $(P<0.01)$ or had a history of asthma $(P=0.05)$. $18.2 \%$ of children reported current exposure to ETS. The prevalence of ETS exposure in the home was $16.1 \%$, and of the children 12-14 years, $7.2 \%$ were present when their peers were smoking. Neither exposure to smoking nor farming was significantly associated with the phenotypes under study.

More children had the heterozygous variant type $(\mathrm{C} / \mathrm{T})$ of CD14 C-159T (52.9\%) than either the C/C wild type $(29.3 \%)$ or T/T homozygous variant $(17.8 \%)$. The distribution of genotypes for CD14 G-1359T was as follows: $\mathrm{G} / \mathrm{G}=56.5 \%$, $\mathrm{G} / \mathrm{T}=35.8 \%$, and $\mathrm{T} / \mathrm{T}=7.7 \%$. All allele frequencies for each SNP under study were in Hardy-Weinberg equilibrium.
Table 2 presents univariate relationships between asthma, atopy, and croup and SNPs using Fisher's exact tests. Croup was reported less frequently for those with the $\mathrm{C} / \mathrm{C}$ genotype of CD14 C-159T (2.6\% versus 8.2 and $8.4 \%$ for $\mathrm{C} / \mathrm{T}$ and $\mathrm{T} / \mathrm{T}$ genotypes, resp.). Asthma was most prevalent for those with the T/T genotype of CD14 G-1359T (26.8\%) and had the lowest prevalence for those with the G/G genotype $(P=$ $0.10)$. Allergy was not significantly associated with genotypes of either SNPs (Table 2).

The multivariate analyses conducted separately for asthma, croup, and atopy are displayed in Table 3 for both CD14 C-159T and CD14 G-1359T SNPs. When compared to those with the C/C genotype of CD14 C-159T, children with the $\mathrm{C} / \mathrm{T}$ and $\mathrm{T} / \mathrm{T}$ genotypes, has almost a 4-fold increased risk of croup $(\mathrm{OR}=3.79 ; 95 \% \mathrm{CI}: 1.13,12.74$ for $\mathrm{C} / \mathrm{T}$ and $\mathrm{OR}=$ 3.77; 95\% CI: $0.89,16.03$ for T/T), respectively. Asthma was not significantly associated with any of the CD 14 C-159T genotypes. Compared to those with the G/G genotype of CD14 G-1359T SNP, those with the T/T genotype had an increased risk of asthma (OR $=2.55 ; 95 \% \mathrm{CI}$ : $1.05,6.19)$. The direction of this association was similar for the G/T genotype but did not reach significance $(P>0.05)$ (Table 3$)$. CD14 G-1359T genotypes were not significantly associated with croup or atopy. No significant interactions were found between genotypes of either CD14 SNPs and covariates in all analyses.

3.1. Haplotype Analysis. There was a high level of linkage disequilibrium between certain allelic combinations of the two CD14 SNPs with a $\mathrm{D}^{\prime}$ statistics of 0.918 . The four possible haplotype combinations of alleles for CD14 C-159T and G1359T were $\mathrm{C}|\mathrm{G}, \mathrm{C}| \mathrm{T}, \mathrm{T} \mid \mathrm{G}$, and $\mathrm{T} \mid \mathrm{T}$. Of the potential haplotype combinations, $43 \%$ of the population had the $\mathrm{T} \mid \mathrm{G}$ haplotype, $31 \%$ had the $\mathrm{C} \mid \mathrm{G}$ haplotype (reference category), and $25 \%$ had the $\mathrm{T} \mid \mathrm{G}$ haplotype. A very small percentage of subjects (1\%) had the T|T haplotype combination. We could not perform the haplotype analysis due to the zero cell count of the T|T haplotype for those who had reported croup. However, this haplotype was associated with asthma $(P=0.014)$. No haplotype association was noted for atopy (Table 3 ).

\section{Discussion}

This study explored the importance of two SNPs in the promoter region of CD14 for asthma, croup, and atopy in a general population of school children. The $\mathrm{C} / \mathrm{T}$ genotype of the CD14 C-159T SNP was associated with an increased risk for croup. We also observed that the T/T genotype of CD14 G-1359T SNP was important in the expression of asthma while the CD14 C-159T, an SNP commonly evaluated in studies for associations with asthma and atopy, was not. All associations between phenotypes under study and CD14 SNPs were independent of reported exposures to smoking and farm living.

There was strong linkage disequilibrium between polymorphisms in the analysis of haplotype associations. Our findings suggest that the haplotype associations of these two polymorphisms are of limited importance for asthma, atopy, 
TABLE 1: Demographics characteristics of asthma, atopy, and croup groups.

\begin{tabular}{|c|c|c|c|c|c|c|}
\hline \multirow{2}{*}{ Characteristics } & \multicolumn{2}{|c|}{ Asthma $(n=533)$} & \multicolumn{2}{|c|}{ Atopy $(n=499)$} & \multicolumn{2}{|c|}{ Croup $(n=533)$} \\
\hline & $\begin{array}{c}\text { Yes } \\
n(\%)\end{array}$ & $\begin{array}{c}\text { No } \\
n(\%)\end{array}$ & $\begin{array}{c}\text { Yes } \\
n(\%)\end{array}$ & $\begin{array}{c}\text { No } \\
n(\%)\end{array}$ & $\begin{array}{c}\text { Yes } \\
n(\%)\end{array}$ & $\begin{array}{c}\text { No } \\
n(\%)\end{array}$ \\
\hline Mean age (SD) years & $9.7(2.2)$ & $9.9(2.3)$ & $10.3(2.3)^{\#}$ & $9.8(2.3)$ & $10.5(2.4)$ & $9.8(2.3)$ \\
\hline \multicolumn{7}{|l|}{ Sex } \\
\hline Male & $56(22.0)^{\#}$ & $199(78.0)$ & $68(27.6)^{* *}$ & $178(72.4)$ & $18(7.1)$ & 237 (92.9) \\
\hline Female & $43(15.5)$ & $235(84.5)$ & $44(17.4)$ & $209(82.6)$ & $17(6.1)$ & $261(93.9)$ \\
\hline \multicolumn{7}{|l|}{ ETS exposure } \\
\hline Yes & 19 (19.6) & $78(80.4)$ & $19(20.4)$ & $74(79.6)$ & $8(8.2)$ & $89(91.8)$ \\
\hline No & $80(18.3)$ & $356(81.7)$ & $93(22.9)$ & $313(77.1)$ & $27(6.2)$ & $409(93.8)$ \\
\hline \multicolumn{7}{|l|}{ Farming exposure } \\
\hline Yes & $45(20.5)$ & $175(79.5)$ & $46(21.7)$ & $166(78.3)$ & $13(5.9)$ & $207(94.1)$ \\
\hline No & $54(17.3)$ & $259(82.7)$ & $66(23.0)$ & $221(77.0)$ & $22(7.0)$ & $291(93.0)$ \\
\hline
\end{tabular}

${ }^{* *} P<0.01,{ }^{*} P<0.10$.

Mean comparison of yes/no groups performed using Student's $t$-test. Frequency comparison of yes/no groups performed using Chi-square test. $n$ number and the numbers in parenthesis are the percentages.

TABLE 2: Distribution of CD14 polymorphism and haplotypes by asthma, atopy, and croup.

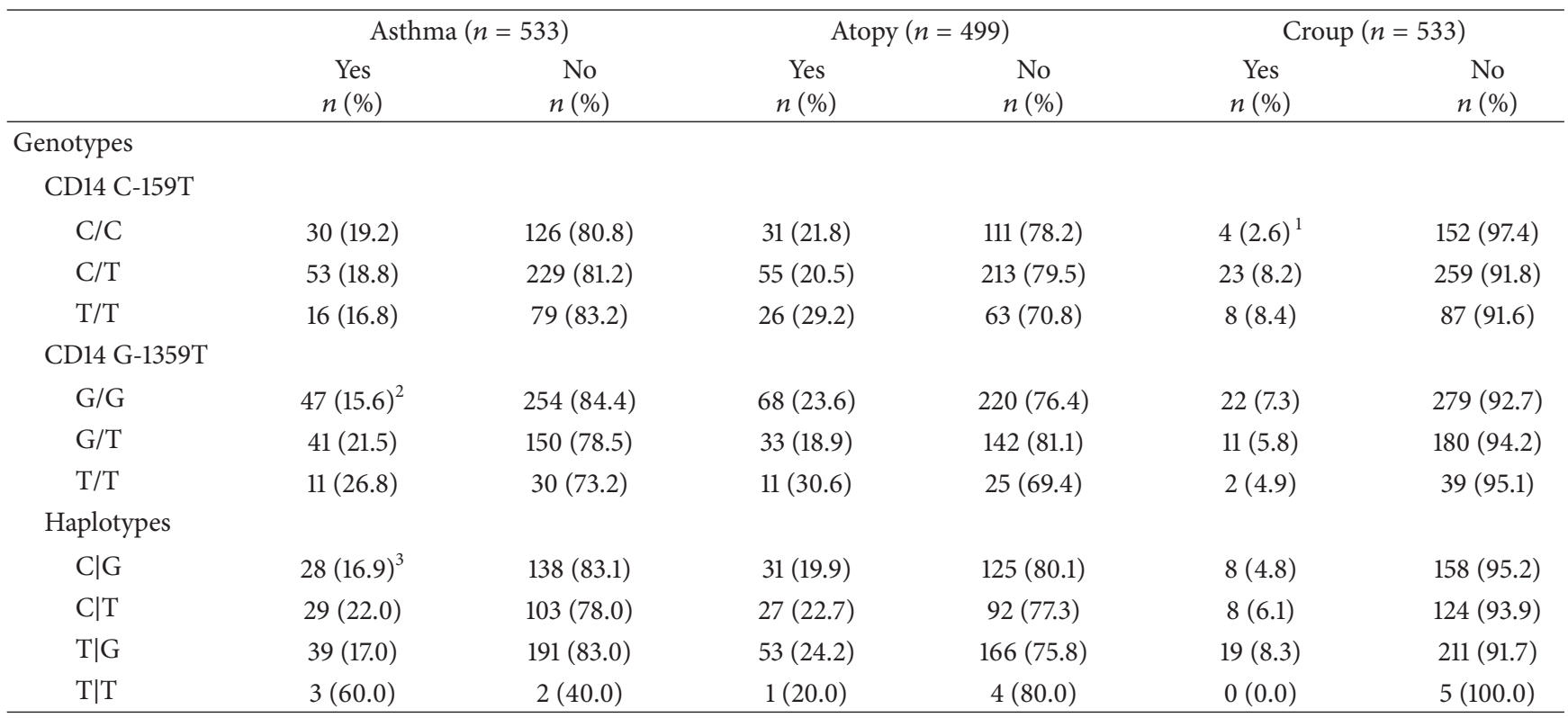

$n$ number and the numbers in parenthesis are the percentages. For genotype and haplotype analysis, significance difference of yes/no groups was performed using Fisher's exact test.

${ }^{1} P=0.05,{ }^{2} P=0.10,{ }^{3} P=0.06$.

and croup. The only significant association was seen for a small number of children who had asthma and the $\mathrm{T} \mid \mathrm{T}$ haplotype combination. Furthermore, no children with croup had the T|T haplotype restricting the analysis for croup.

The results of previous studies investigating relationships between CD14 C-159T polymorphism and asthma or allergy demonstrate considerable variation in the direction of associations and the significant genotypes involved. Similar to our study, other studies have found no association between CD14 C-159T genotypes and asthma [14-16, 20-24].

Importantly, our study found that children with either the $\mathrm{C} / \mathrm{T}$ or $\mathrm{T} / \mathrm{T}$ variants of CD14 C-159T polymorphism were more likely to have a history of croup than those with the $\mathrm{C} / \mathrm{C}$ variant. The findings of polymorphisms associated with croup are novel. The low prevalence of croup in children with the homozygous $\mathrm{C} / \mathrm{C}$ (2.6\% versus $8.2-8.4 \%$ with other variants of CD14 C-159T) suggests that children with the $\mathrm{C} / \mathrm{C}$ variant are more protected against croup illness in childhood.

The primary agents reported to be responsible for croup are the Para influenza viruses, although the respiratory syncytial virus (RSV) has also been identified as a causative agent [12]. Besides the primary role of CD14 as a coreceptor with TLR4 and MD-2 in the detection of LPS, the CD14 gene is also important in the recognition of mediator cells of other 
TABLE 3: Multivariate logistic regression adjusted odds ratios for respiratory conditions for selected CD14 polymorphisms and haplotypes.

\begin{tabular}{|c|c|c|c|}
\hline Models & $\begin{array}{c}\text { Asthma }(n=533) \\
\text { OR }(95 \% \mathrm{CI})^{\#}\end{array}$ & $\begin{array}{c}\text { Atopy }(n=499) \\
\text { OR }(95 \% \mathrm{CI})^{\#}\end{array}$ & $\begin{array}{c}\text { Croup }(n=533) \\
\text { OR }(95 \% \mathrm{CI})^{\#}\end{array}$ \\
\hline \multicolumn{4}{|c|}{ Genotypes model } \\
\hline \multicolumn{4}{|c|}{ CD14 C-159T } \\
\hline $\mathrm{C} / \mathrm{C}$ & 1.00 & 1.00 & 1.00 \\
\hline $\mathrm{C} / \mathrm{T}$ & $1.20(0.68,2.11)$ & $0.97(0.55,1.72)$ & $3.79(1.13,12.74)$ \\
\hline $\mathrm{T} / \mathrm{T}$ & $1.37(0.61,3.06)$ & $1.40(0.67,2.94)$ & $3.77(0.89,16.03)$ \\
\hline \multicolumn{4}{|c|}{ CD14 G-1359T } \\
\hline $\mathrm{G} / \mathrm{G}$ & 1.00 & 1.00 & 1.00 \\
\hline $\mathrm{G} / \mathrm{T}$ & $1.65(0.97,2.80)$ & $0.86(0.51,1.45)$ & $0.98(0.43,2.25)$ \\
\hline $\mathrm{T} / \mathrm{T}$ & $2.55(1.05,6.19)$ & $1.63(0.67,3.97)$ & $1.71(0.31,9.52)$ \\
\hline \multicolumn{4}{|c|}{ Haplotypes model } \\
\hline $\mathrm{C} \mid \mathrm{G}$ & 1.00 & 1.00 & 1.00 \\
\hline $\mathrm{C} \mid \mathrm{T}$ & $1.36(0.88,2.10)$ & $1.16(0.77,1.75)$ & $\$$ \\
\hline $\mathrm{T} \mid \mathrm{G}$ & $1.04(0.69,1.57)$ & $1.21(0.82,1.79)$ & $\$$ \\
\hline $\mathrm{T} \mid \mathrm{T}$ & $7.17(1.49,34.40)$ & $0.73(0.08,6.39)$ & $\$$ \\
\hline
\end{tabular}

${ }^{\#}$ Adjusted for age, sex, ETS, and farming exposure. OR: odds ratio; CI: confidence interval. ${ }^{\$}$ Not reported due to zero counts in the cell of T|T with croup (see Table 2). Significance results are bold.

proinflammatory agents including viruses [5]. Thus it seems likely that the CD14 gene may influence the innate immune response to a viral associated condition such as croup. To our knowledge the assessment of the potential roles of CD14 SNPs in the expression of croup has not been previously reported.

Study results surrounding the -159 SNP and allergic phenotypes have been controversial. A decreased serum IgE level in those who were also SPT positive has been associated the $\mathrm{T} / \mathrm{T}$ genotype $[13,21]$, while an increased serum IgE level has been associated with the $\mathrm{C} / \mathrm{C}$ genotype in another study but only in skin positive subjects [16]. Atopic evaluation by SPT may have more relevance for the CD14 C-159T polymorphism $[14,16,17,19]$, and specific allergens may be of special interest $[14,19]$.

Our findings add to current understanding of the potential importance of the CD14 G-1359T SNP for asthma phenotypes. Previous studies to date have found no association between CD14 G-1359T and asthma or asthma related symptoms $[14,24]$. However, the -1359 genotypes, particularly with the $\mathrm{G} / \mathrm{G}$ variant appear to be important for house dust mite (HDM) atopy $[23,35]$.

Environmental endotoxin exposures such as those found in homes, in farms, or with cigarette smoke can be effect modifiers in the associations between asthma, asthma-like symptoms, or atopy and the CD14 C-159T genotypes $[19,28$, $36,37]$. In this study, neither smoking nor farming exposures notably altered the statistical associations between any of the SNPs and phenotypes under study.

This study is characterized by excellent response rates to the questionnaire, skin testing and genetic testing, and provides support for the role of two CD14 SNPs at -1359 and -159 for asthma and croup phenotypes. The distributions reported in this study of CD14 C-159T genotypes were similar to previously reported information for children $[13,14,17,20$, 24].
A potential limitation of this study is the use of questionnaire data to define two of the three phenotypes evaluated here (i.e., asthma and croup). Questionnaire reports of physician reported asthma have been used by others and have been found to be reliable [38, 39]. However, associations identified still require careful consideration of the lack of a gold standard for asthma at this time.

We relied on parental recall of croup, which could have led to potential misclassification of the phenotype, particularly for parents of older children, as this condition usually occurs between 6 months and 5 years of age [12]. However, croup is a dramatic, acute condition of the airways that often requires hospital emergency room intervention [8] and, as such, might assist in its recall by parents [7].

We were unable to control certain potential inheritable or congenitally related risk factors in our multivariate analysis for croup including croup frequency, family history of croup, gastroesophageal reflux, and anatomical variations. Family history has been reported to be associated with both recurrent and first episode of croup [10]. The frequency of gastroesophageal reflux in the current study was very low (1.7\%), limiting its usefulness for the analyses. This study did not lend itself to assessment of anatomical variations associated with croup, although a previous study identified that $49 \%$ of children with recurrent croup who underwent endoscopy had a grade 1, mildly abnormal, subglottic stenosis [40]. Thus, further information on causative agents of physician diagnosed croup and knowledge of the responsible agent would be important in determining why those with the $\mathrm{C} / \mathrm{C}$ variant of CD14 C-159T were less likely to report a history of croup.

This study identified associations between asthma with CD14 G-1359T polymorphism that has only been previously noted for atopy and serum IgE. The -159 polymorphism of CD14 appears to play a role in the expression of croup, and a much wider examination of the role of other genes is 
required through genome wide association studies. Further investigation of the role of genetic influences for croup should be considered. For a limited number of children with the homologous alleles T/T of CD14 C-159T and G-1359T, there may be an increased risk of asthma.

\section{Acknowledgments}

This study was supported by a grant from the Canadian Institutes of Health Research Endotoxin and the Lung (Grant no. MOP-57907). Special thanks go to Mr. Keigo Yurube for his contribution to genotyping analysis. The contribution of all the children and parents who donated their time to this study and the schools who permitted access to the children was invaluable.

\section{References}

[1] R. J. Rosychuk, D. C. Voaklander, T. P. Klassen, A. Senthilselvan, T. J. Marrie, and B. H. Rowe, "Asthma presentations by children to emergency departments in a Canadian province: a population-based study," Pediatric Pulmonology, vol. 45, no. 10, pp. 985-992, 2010.

[2] R. J. Rosychuk, T. P. Klassen, D. Metes, D. C. Voaklander, A. Senthilselvan, and B. H. Rowe, "Croup presentations to emergency departments in Alberta, Canada: a large populationbased study," Pediatric Pulmonology, vol. 45, no. 1, pp. 83-91, 2010.

[3] R. Zoorob, M. Sidani, and J. Murray, "Croup: an overview," American Family Physician, vol. 83, no. 9, pp. 1067-1073, 2011.

[4] R. Tesse, R. C. Pandey, and M. Kabesch, "Genetic variations in toll-like receptor pathway genes influence asthma and atopy," Allergy, vol. 66, no. 3, pp. 307-316, 2011.

[5] R. Arroyo-Espliguero, P. Avanzas, S. Jeffery, and J. C. Kaski, "CD14 and toll-like receptor 4: a link between infection and acute coronary events?” Heart, vol. 90, no. 9, pp. 983-988, 2004.

[6] M. A. Dobrovolskaia and S. N. Vogel, "Toll receptors, CD14, and macrophage activation and deactivation by LPS," Microbes and Infection, vol. 4, no. 9, pp. 903-914, 2002.

[7] T. Nicolai and E. V. Mutius, "Risk of asthma in children with a history of croup," Acta Paediatrica, vol. 85, no. 11, pp. 1295-1299, 1996.

[8] H. P. Van Bever, M. H. Wieringa, J. J. Weyler, V. J. Nelen, M. Fortuin, and P. A. Vermeire, "Croup and recurrent croup: their association with asthma and allergy: an epidemiological study on 5-8-year-old children," European Journal of Pediatrics, vol. 158, no. 3, pp. 253-257, 1999.

[9] Z. Arslan, F. E. Çipe, S. Özmen, M. Kondolot, I. E. Piskin, and A. Yöney, "Evaluation of allergic sensitization and gastroesophageal reflux disease in children with recurrent croup," Pediatrics International, vol. 51, no. 5, pp. 661-665, 2009.

[10] H. Pruikkonen, T. Dunder, M. Renko, T. Pokka, and M. Uhari, "Risk factors for croup in children with recurrent respiratory infections: a case-control study," Paediatric and Perinatal Epidemiology, vol. 23, no. 2, pp. 153-159, 2009.

[11] J. A. Castro-Rodríguez, C. J. Holberg, W. J. Morgan et al., "Relation of two different subtypes of croup before age three to wheezing, atopy, and pulmonary function during childhood: a prospective study," Pediatrics, vol. 107, no. 3, pp. 512-518, 2001.

[12] S. E. Sobol and S. Zapata, "Epiglottitis and croup," Otolaryngologic Clinics of North America, vol. 41, no. 3, pp. 551-566, 2008.
[13] M. Baldini, I. C. Lohman, M. Halonen, R. P. Erickson, P. G. Holt, and F. D. Martinez, "A polymorphism in the 5 ' flanking region of the CD14 gene is associated with circulating soluble CD14 levels and with total serum immunoglobulin E," American Journal of Respiratory Cell and Molecular Biology, vol. 20, no. 5, pp. 976983, 1999.

[14] D. Bučková, L. I. Hollá, M. Schüller, V. Znojil, and J. Vácha, "Two CD14 promoter polymorphisms and atopic phenotypes in Czech patients with IgE-mediated allergy," Allergy, vol. 58, no. 10, pp. 1023-1026, 2003.

[15] L. A. M. Smit, S. I. M. Bongers, H. J. T. Ruven et al., "Atopy and new-onset asthma in young Danish farmers and CD14, TLR2, and TLR4 genetic polymorphisms: a nested case-control study," Clinical and Experimental Allergy, vol. 37, no. 11, pp. 1602-1608, 2007.

[16] G. H. Koppelman, N. E. Reijmerink, O. C. Stine et al., "Association of a promoter polymorphism of the CD14 gene and atopy," American Journal of Respiratory and Critical Care Medicine, vol. 163, no. 4, pp. 965-969, 2001.

[17] A. R. O’Donnell, B. G. Toelle, G. B. Marks et al., "Age specific relationship between CD14 and atopy in a cohort assessed from age 8 to 25 years," American Journal of Respiratory and Critical Care Medicine, vol. 169, no. 5, pp. 615-622, 2004.

[18] T. D. LeVan, S. von Essen, D. J. Romberger et al., "Polymorphisms in the CD14 gene associated with pulmonary function in farmers," American Journal of Respiratory and Critical Care Medicine, vol. 171, no. 7, pp. 773-779, 2005.

[19] A. Simpson, S. L. John, F. Jury et al., "Endotoxin exposure, CD14, and allergic disease: an interaction between genes and the environment," American Journal of Respiratory and Critical Care Medicine, vol. 174, no. 4, pp. 386-392, 2006.

[20] M. Kabesch, K. Hasemann, V. Schickinger et al., "A promoter polymorphism in the CD14 gene is associated with elevated levels of soluble CD14 but not with IgE or atopic diseases," Allergy, vol. 59, no. 5, pp. 520-525, 2004.

[21] C. Sengler, A. Haider, C. Sommerfeld et al., "Evaluation of the CD14-C-159-T polymorphism in the German Multicenter Allergy Study cohort," Clinical and Experimental Allergy, vol. 33, no. 2, pp. 166-169, 2003.

[22] P.-S. Gao, X.-Q. Mao, M. Baldini et al., "Serum total IgE levels and CD14 on chromosome 5q31," Clinical Genetics, vol. 56, no. 2, pp. 164-165, 1999.

[23] C.-Y. Tan, Y.-L. Chen, L. S.-H. Wu, C.-F. Liu, W.-T. Chang, and J.-Y. Wang, "Association of CD14 promoter polymorphisms and soluble CD14 levels in mite allergen sensitization of children in Taiwan," Journal of Human Genetics, vol. 51, no. 1, pp. 59-67, 2006.

[24] A. Heinzmann, H. Dietrich, S.-P. Jerkic, T. Kurz, and K. A. Deichmann, "Promoter polymorphisms of the CD14 gene are not associated with bronchial asthma in Caucasian children," European Journal of Immunogenetics, vol. 30, no. 5, pp. 345-348, 2003.

[25] C. Saçkesen, C. Karaaslan, O. Keskin et al., "The effect of polymorphisms at the CD14 promoter and the TLR4 gene on asthma phenotypes in Turkish children with asthma," Allergy, vol. 60, no. 12, pp. 1485-1492, 2005.

[26] C. Ober and E. E. Thompson, "Rethinking genetic models of asthma: the role of environmental modifiers," Current Opinion in Immunology, vol. 17, no. 6, pp. 670-678, 2005.

[27] C. Ober and S. Hoffjan, "Asthma genetics 2006: the long and winding road to gene discovery," Genes and Immunity, vol. 7, no. 2, pp. 95-100, 2006. 
[28] D. Vercelli, M. Baldini, and F. D. Martinez, "The monocyte/IgE connection: may polymorphisms in the CD14 gene teach us about IgE regulation?" International Archives of Allergy and Immunology, vol. 124, no. 1-3, pp. 20-24, 2001.

[29] B. G. Ferris, "Epidemiology standardization project," American Review of Respiratory Disease, vol. 118, supplement 6, pp. 1-120, 1978.

[30] Y. Chen, D. C. Rennie, and J. A. Dosman, "Influence of environmental tobacco smoke on asthma in nonallergic and allergic children," Epidemiology, vol. 7, no. 5, pp. 536-539, 1996.

[31] A. Høst, S. Andrae, S. Charkin et al., "Allergy testing in children: why, who, when and how?” Allergy, vol. 58, no. 7, pp. 559-569, 2003.

[32] B. Richards, J. Skoletsky, A. P. Shuber et al., "Multiplex PCR amplification from the CFTR gene using DNA prepared from buccal brushes/swabs," Human Molecular Genetics, vol. 2, no. 2, pp. 159-163, 1993.

[33] R Development Core Team, "R: a language and environment for statistical computing," R Foundation for Statistical Computing, Vienna, Austria, 2006, http://www.r-project.org/.

[34] A. S. Foulkes, Applied Statistical Genetics with R: For PopulationBased Association Studies, Springer, New York, NY, USA, 2009.

[35] M. Kurowski, B. Majkowska-Wojciechowska, A. Wardzyńska, and M. L. Kowalski, "Associations of allergic sensitization and clinical phenotypes with innate immune response genes polymorphisms are modified by house dust mite allergen exposure," Archives of Medical Science, vol. 7, no. 6, pp. 1029-1036, 2011.

[36] F. D. Martinez, "CD14, endotoxin, and asthma risk: actions and interactions," Proceedings of the American Thoracic Society, vol. 4, no. 3, pp. 221-225, 2007.

[37] I. A. Yang, S. Savarimuthu, S. T. Kim, J. W. Holloway, S. C. Bell, and K. M. Fong, "Gene-environmental interaction in asthma," Current Opinion in Allergy and Clinical Immunology, vol. 7, no. 1, pp. 75-82, 2007.

[38] M. I. Asher, U. Keil, H. R. Anderson et al., "International study of asthma and allergies in childhood (ISAAC): rationale and methods," European Respiratory Journal, vol. 8, no. 3, pp. 483491, 1995.

[39] J. K. Peat, R. H. van den Berg, W. F. Green, C. M. Mellis, S. R. Leeder, and A. J. Woolcock, "Changing prevalence of asthma in Australian children," British Medical Journal, vol. 308, no. 6944, pp. 1591-1596, 1994.

[40] N. Jabbour, N. P. Parker, M. Finkelstein, T. A. Lander, and J. D. Sidman, "Incidence of operative endoscopy findings in recurrent croup," Padiatric Otolaryngology, vol. 144, no. 4, pp. 596-601, 2011. 


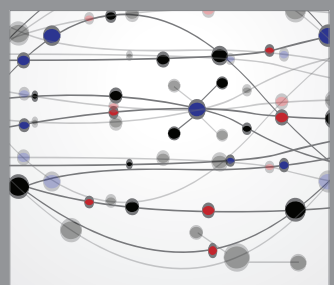

The Scientific World Journal
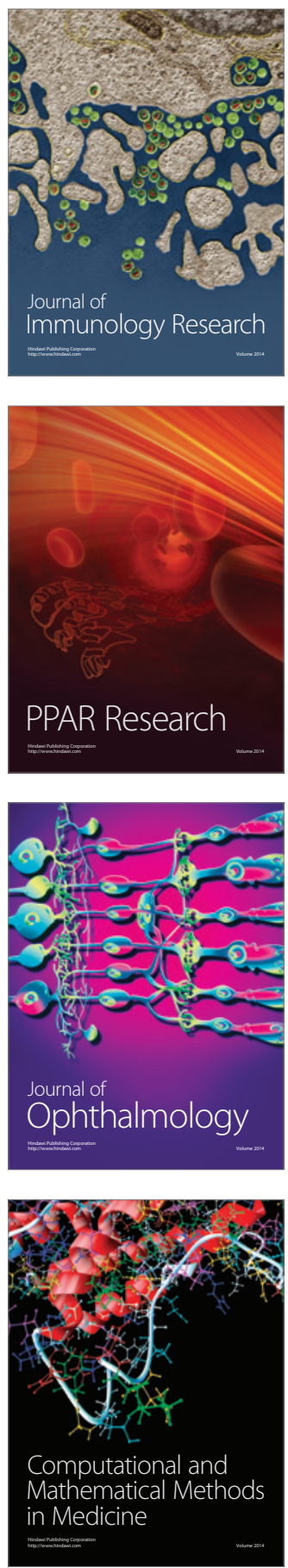

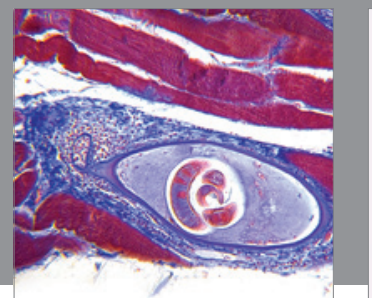

Gastroenterology

Research and Practice
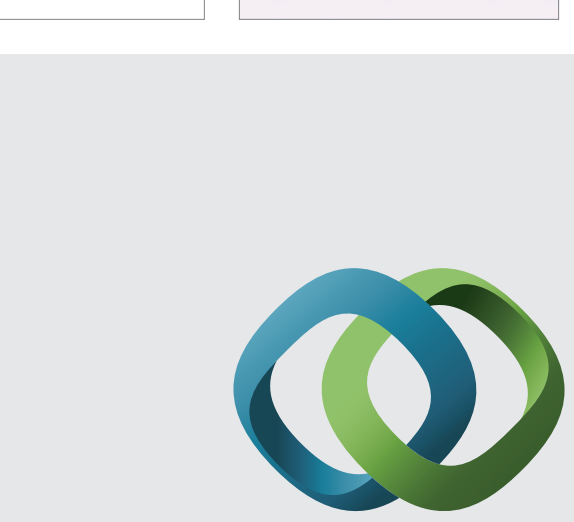

\section{Hindawi}

Submit your manuscripts at

http://www.hindawi.com
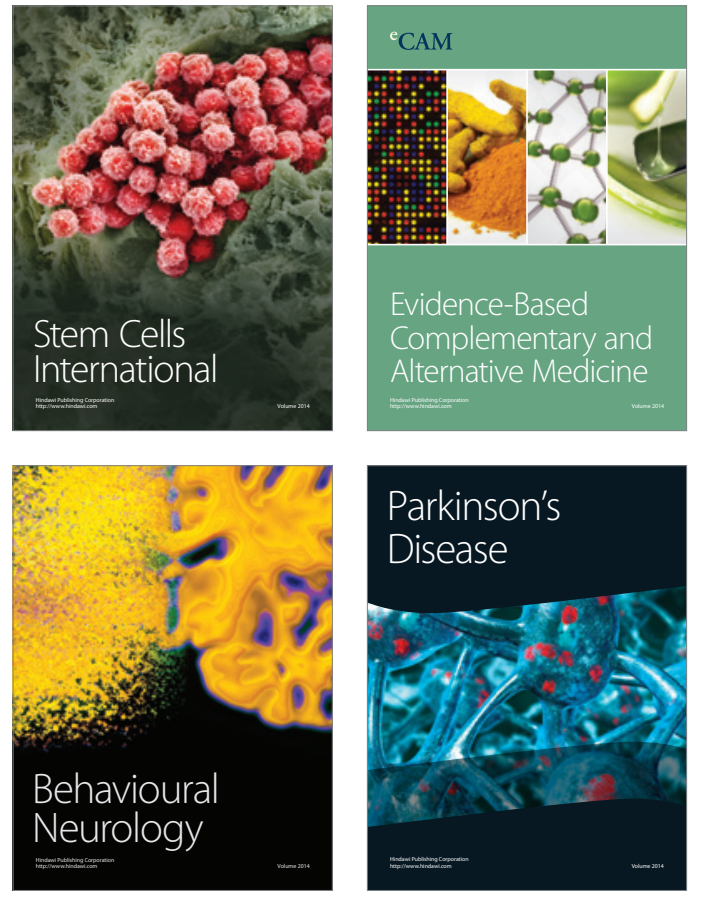
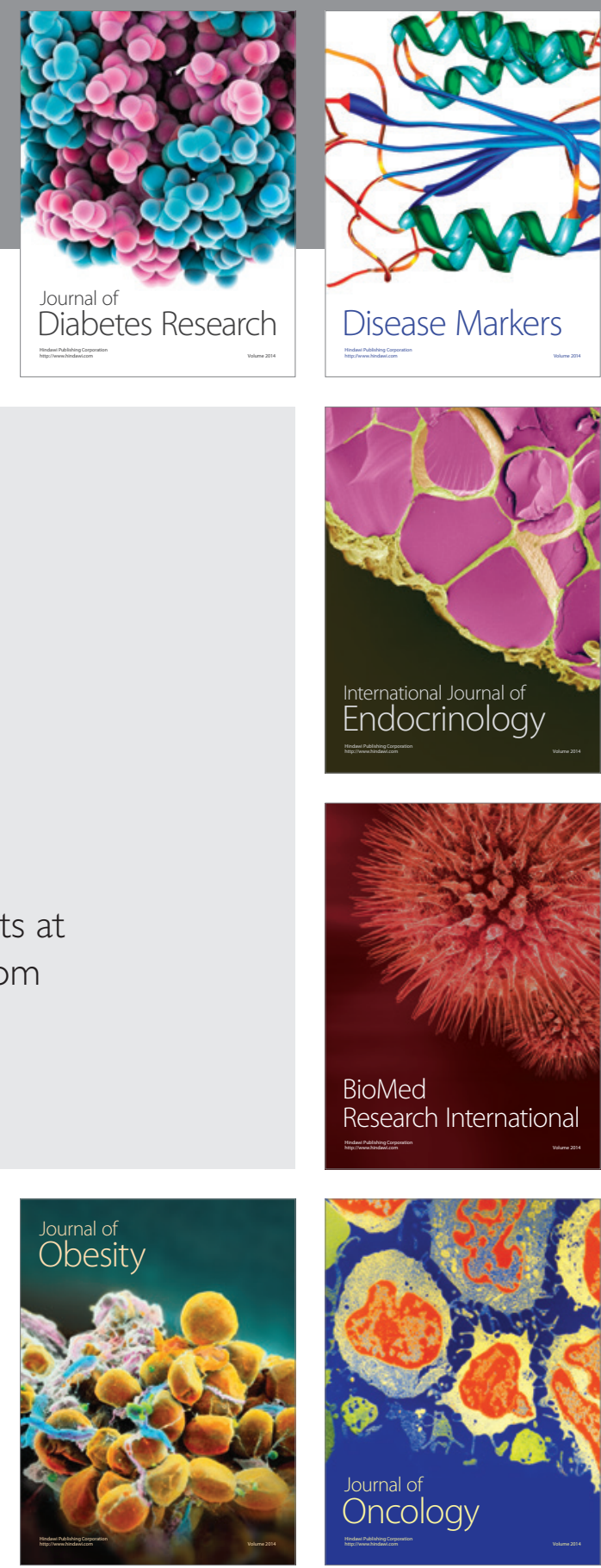

Disease Markers
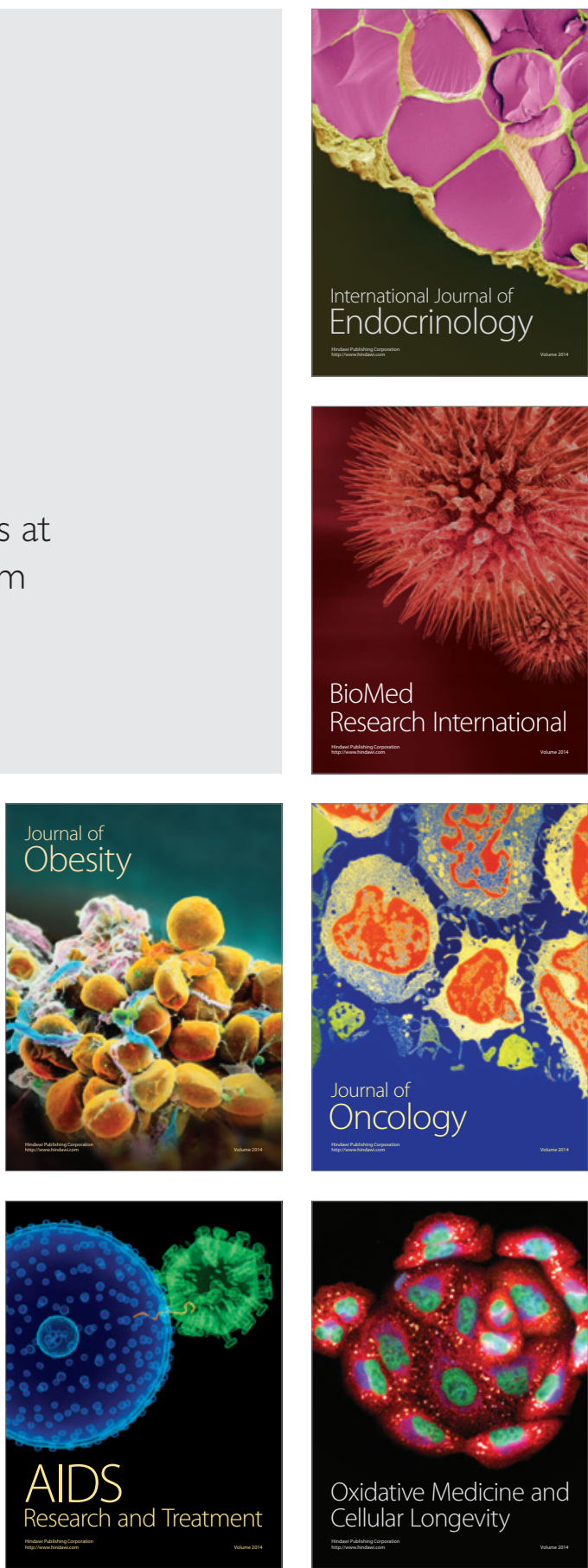